\title{
Exploring the Effects of Mindfulness and Self-Distancing on Chocolate Intake After a Negative State Affect
}

\author{
Misba Hussain $^{1}$ (D) Helen Egan ${ }^{1} \cdot$ Rebecca Keyte $^{1} \cdot$ Michail Mantzios $^{1}$
}

Received: 1 April 2020 / Accepted: 16 June 2020 / Published online: 2 July 2020

(C) The Author(s) 2020

\begin{abstract}
Foods high in fat and sugar can often act as emotional regulators during negative emotional states, and regularly engaging in such behaviour can contribute towards weight gain. The present study investigated whether using mindful construal diaries (MCD) adapted with the element of self-distancing could improve state mindfulness, attenuate negative affect, and reduce chocolate intake. One hundred twenty participants were randomly assigned to one of three conditions, self-immersed, self-distanced, and control, and after evoking a negative state affect through a film excerpt, participants were served chocolate. The findings suggested there were no significant differences in improving state mindfulness or state negative affect across the three conditions. However, participants in the control condition did consume significantly more chocolate than those in the self-immersed and self-distanced conditions. Whilst there were no significant differences in chocolate intake between the two experimental conditions, those in the self-distanced condition did consume the least amount of chocolate. The concept of self-distancing may be beneficial in improving emotional eating behaviours further in mindful and attentive eating interventions. Limitations and recommendations for future research are discussed.
\end{abstract}

Keywords Mindfulness $\cdot$ Self-distanced $\cdot$ Emotional eating $\cdot$ Negative state affect $\cdot$ Chocolate intake

Research suggests that emotion regulation can derive from some foods, which are often high in fat and sugar and may be understood as "comfort foods" (Macht and Mueller 2007), temporarily diminishing negative mood and evoking a state of pleasure (e.g. Scholey and Owen 2013; Wansink et al. 2003). For example, Macht and Dettmer (2006) found participants reported a positive mood after eating chocolate in comparison with those eating an apple or nothing. Similarly, other experimental research found eating chocolate versus drinking water significantly reduced negative state mood (Macht and Mueller 2007). Frequently engaging in eating to improve affect can lead to excessive energy intake and may contribute towards weight gain and obesity (e.g. van Strien 2018; Konttinen et al. 2019).

Literature on trait eating styles, such as emotional and restrained eating, and their influence upon negative mood that leads to consumption is inconsistent. Some studies suggest high emotional eaters increase their food intake after a

Misba Hussain

Misba.Hussain@mail.bcu.ac.uk

1 Department of Psychology, Faculty of Business, Law and Social Sciences, Birmingham City University, The Curzon Building, 4 Cardigan St., Birmingham B4 7BD, UK negative mood induction, and consume more sweet and high-fat foods than non-emotional eaters (Loxton et al. 2011; Yeomans and Coughlan 2009). Others report that emotional eating traits do not have an influence on food intake (e.g. Evers et al. 2010). Furthermore, findings on restrained eating and negative affect also appear to be conflicting. Whilst some researchers argue negative affects prompt overconsumption in people attempting to restrict their caloric intake (Schotte et al. 1990; Wallis and Hetherington 2004), others have reported that the relationship between restrained eaters and overeating in response to negative moods is not so direct (e.g. Herman et al. 1987; Yeomans and Coughlan 2009). Such findings suggest emotional and restrained eating behaviours may not necessarily lead to overconsumption, but rather the experimental induction in replicating natural states of negative emotion may promote increased energy intake. Therefore, it is important to find means that moderate the consumption of calorie-dense foods during episodes of negative affect to prevent overeating and risk of weight gain (Canetti et al. 2002; Lazarevich et al. 2016; Macht 2008).

Mindfulness may be a variable that could moderate the association between negative affect and overconsumption (Meier et al. 2017). Mindfulness is an awareness that emerges through purposefully paying attention to what is taking place 
in the present moment with a non-judgmental attitude (KabatZinn 1990). Over recent years, there has been an extensive amount of research associating mindfulness with healthier eating behaviours, such as, promoting healthier food choices, reducing fat and sugar consumption, as well as susceptibility to hunger cues (Dutt et al. 2019; Marchiori and Papies 2014). In a study more specifically related to affect and consumption, Meier et al. (2017) found participants who were instructed to mindfully eat chocolate had a greater increase in positive mood compared with participants who were instructed to eat chocolate non-mindfully or crackers either mindfully or nonmindfully. Mindfulness may then enhance pleasure, and enable people to regulate their consumption of calorie-dense foods whilst also self-regulating mood (Meier et al. 2017).

In an attempt to induce mindful eating, Mantzios and Wilson (2014) developed a non-meditative mindful eating tool referred to as the "mindful concrete construal diary" or mindful construal diary (MCD) promoting mindfulness and self-compassion through construal level methods. The tool is used during each meal and individuals are encouraged to be present in the moment, whilst also being kind and non-judgmental to their thoughts and feelings that may arise whilst eating (Mantzios and Wilson 2014). Construal level theory (CLT) describes an identification on a close or distant continuum (Liberman and Trope 1998). Distant objects, events, and individuals are portrayed as abstract construals as they consider why actions are being performed, whilst, close objects, events, or individuals are represented as concrete construals as they focus on how they carry out behaviour (Freitas et al. 2004). For example, whilst eating, a person thinking concretely will consider how their food tastes right now, and how healthy they perceived it to be, whereas, abstract thinking will focus on why this meal is healthy. The MCD has shown improvements in promoting healthier behaviours, such as reducing portion size effect, encouraging fruit consumption, improving weight loss, and psychological well-being (Hussein et al. 2017; Hussain et al. 2020a, b; Mantzios and Wilson 2014). The current research proposes another element that has not yet been explored in relation to eating behaviours, but has been found to successfully reduce emotional distress and enable people to cope with negative emotions, namely, self-distancing (e.g. Ayduk and Kross 2010a, b).

The act of expressive writing, whereby people explore emotional trauma, has demonstrated physical and psychological health benefits (Frisina et al. 2004; King and Miner 2000); however, such benefits are only apparent when people reflect on these events through a self-distanced perspective (Mischkowski et al. 2012; Nolen-Hoeksema 1991). Research illustrates when people are self-immersed (i.e. look at a perspective from their own point of view) whilst analysing distressing memories, they are predisposed to focus narrowly on recounting the intense details of their experience, which could perpetuate further negative emotions. Contrary, when people adopt a self-distanced perspective (i.e. look at a perspective from a distanced viewpoint), they are able to understand the broader context of the situation by being able to step away from the role of a victim and reconstrue their experience, which, in effect, can lead to less distress (e.g. Kross and Ayduk 2011). Adopting a self-distanced role has shown to lower blood pressure reactivity, reduce depression and affect, and improve coping with social anxiety and stress (Kross et al. 2014).

The MCD has previously been adjusted through simple linguistic adaptations to create a connotation of selfcompassion and mindfulness through concrete construals (Hussain et al. 2020c). To form a self-distanced perspective of the MCD, linguistic adaptations were specifically implemented for the present study. For example, the MCD typically encourages people to reflect on their eating behaviour through a self-immersed perspective, such as, "How kind are you to yourself whilst you are eating this meal?" (Mantzios and Wilson 2014), and by doing so, the self who conducts the behaviour and the self who is reasoning the behaviour are the same. Divergently, using a self-distanced perspective, such as, "How kind is Tom being to himself while he is eating this meal?", the person can take a step back and view their behaviour from a distanced perspective, potentially allowing them to manage their eating behaviour with more acceptance and non-judgment. Research on CLT suggests that psychological distance allows people to adopt broader perspectives on events, helping people to see the bigger picture rather than focusing on concrete details (Fujita et al. 2006; Liberman \& Trope 2008), which was achieved through mindfulness and self-compassion in the MCD, whilst maintaining concrete perspectives on the present meal and eating experience.

Psychological distance from the situation has been considered in previous literature as not adhering to mindfulness principles (e.g. considering past and future behaviours-see Mantzios and Wilson 2014); however, distancing oneself from the situation may be a means of overcoming affect that arises and disrupts the mindful and self-compassionate engagement within the situation. Literature has repeatedly identified how people find it easier to be kind to loved ones, but rather more difficult to express kindness towards oneself (Egan and Mantzios 2018; Mantzios and Wilson 2015). Therefore, the addition of a self-distanced perspective within the MCD may amplify the effect of regulating consumption when negative mood is further regulated.

The present study investigated whether a self-distanced MCD could improve state mindfulness and state negative affect, and consequently lead to a reduced intake of calorie-dense foods. It was hypothesised prior to data collection that participants in a self-distanced MCD condition would be significantly more likely to improve their state mindfulness, attenuate their negative mood, and consume less chocolate than participants who receive a self-immersed MCD and the control condition. However, this may be effected by eating behaviours, such as emotional eating and restrained eating, which were controlled for in subsequent analyses. 


\section{Method}

\section{Participants}

One hundred twenty participants ( 91 female, 20 male, 9 not specified) were recruited via opportunity sampling from a university in the West Midlands, UK. The sample size was based on the number of participants recruited in other similar studies (e.g. Macht and Mueller 2007; Mantzios et al. 2019, 2020). The mean BMI of the sample $M=22.30(S D=8.48)$ and age $M=24.23(S D=9.49)$, and their self-identified ethnicities were White or White British $(n=43)$, Black African or Caribbean $(n=18)$, Asian $(n=43)$, Middle Eastern $(n=5)$, Chinese $(n=5)$, mixed ethnicity $(n=5)$, and not specified $(n=$ $1)$.

Eligibility Due to the nature of the study, participants who had any food allergies or intolerances (e.g. dairy) were not permitted to participate. Participants were also informed via an information sheet and consent form that they were not eligible to participate if they had been diagnosed with an eating disorder.

\section{Experimental Conditions}

Participants were randomly assigned to one of three conditions, self-immersed $(n=40$; female $=33$, male $=5$, not specified $=2$ ), self-distanced ( $n=40$; female $=35$, male $=4$, not specified $=1)$, and control $(n=40$; female $=23$, male $=11$, not specified $=6$ ). Participants in both experimental conditions received an adapted version of the original MCD (for a full review on the original MCD, see Mantzios and Wilson 2014). Participants in the self-immersed condition received a MCD that was adapted with questions presented in the first person, for example "How do I feel, and what passes through my mind now that I am eating this snack?" and "How important is this snack to me right now?" Participants in the selfdistanced condition received a MCD formatted in the third person, for example "How does Tom feel and what passes through Tom's mind now that he is eating this snack?" and "How important is this snack to Tom right now?" (the adapted MCD can be made available by contacting the first author). Participants in both conditions were asked to simply consider (instead of write) the answers to the questions of the adapted MCD versions (Hussein et al. 2017), and in order to represent a real living condition as much as possible, participants in the control condition did not receive a MCD or any reading task.

\section{Mood Induction}

To induce a negative state affect, an excerpt from a popular movie, "The Champ" was presented, showing a young boy crying at the death of his father (duration, 2 min $51 \mathrm{~s}$ ). The use of this film clip has shown to successfully induce negative emotions amongst different populations (Gross and Levenson 1995; Hagemann et al. 1999; Macht and Mueller 2007; Macht et al. 2002).

\section{Food}

Participants in all three conditions were provided with $100 \mathrm{~g}$ (500 kcal) of Galaxy chocolate minstrels. Although a typical serving size in the UK is approximately $45 \mathrm{~g}(225 \mathrm{kcal})$, a serving of $100 \mathrm{~g}$ was provided in order to avoid artificially limited intake. The chocolate was sourced from UK Tesco stores, and served in a white bowl with the size amounting to width $15 \mathrm{~cm} \times$ length $15 \mathrm{~cm} \times$ height $8 \mathrm{~cm}$.

\section{Assessment Materials}

Participant Information Form Participants were asked questions regarding their gender, age, height, weight, and ethnicity in order to assess their BMI and background information.

Hunger To assess hunger, participants were asked at the start of the experimental session "How hungry do you feel right now?" with responses ranging from 1 (not at all) to 5 (extremely hungry).

Taste Testing In a bogus taste test, participants were asked to rate the likeability of the chocolate after consumption (e.g. "How much did you like the taste of the chocolate minstrels?'), with responses ranging from 1 (not at all) to 7 (extremely).

State Mindfulness Scale (Tanay and Bernstein 2013) The State Mindfulness Scale (SMS) is a 21-item instrument that reflects on traditional and contemporary psychological science models of mindfulness. It includes items such as "I felt that I was experiencing the present moment fully" and "I noticed many small details of my experience". Responses range from 1 (not at all) to 5 (very well), with total scores varying from 21 to 105, higher scores indicating higher levels of state mindfulness. Participants were instructed to complete a state measure after the mood induction (pre), and again after consumption (post). In the current study, the alpha was $(\alpha=.94)$ pre and $(\alpha=.95)$ post.

Positive and Negative Affect Schedule (Watson et al. 1988) The Positive and Negative Affect Schedule (PANAS) is a scale designed to measure both positive and negative affects. In order to measure participants' negative state affect, the present study administered the negative affect subscale.

\footnotetext{
${ }^{1}$ The positive affect subscale from PANAS (Watson et al. 1988) was collected as it was part of the original PANAS scale. However, given that the study was focusing on negative affect, the authors did not conduct any analysis on the positive affect subscale.
} 
Sample items include "distressed" and "upset", and responses range from 1 (very slightly or not at all) to 5 (extremely), with total scores varying from 10 to 50 , lower scores representing lower levels of negative affect. Participants were instructed to complete the negative affect measure at baseline, again after mood induction (pre), and finally after consumption (post). In the current study, the alpha was $(\alpha=.76)$ baseline, $(\alpha=.89)$ pre, and $(\alpha=.85)$ post.

Dutch Eating Behaviour Questionnaire (van Strien et al. $1986)^{2}$ To assess emotional eating and restrained eating behaviours, participants completed the emotional eating and restrained eating subscales of the Dutch Eating Behaviour Questionnaire (DEBQ). Example items from the scales are as follows: "Do you have the desire to eat when you are irritated?" (emotional eating) and "If you put on weight, do you eat less than you usually do?" (restrained eating). Responses range from 1 (never) to 5 (very often), with total scores varying from 12 to 60 (emotional eating) or 10 to 50 (restrained eating), and higher scores suggest increased emotional or restrained eating. In the current study, the alpha was $(\alpha=.90)$ emotional eating and $(\alpha=.91)$ restrained eating.

\section{Procedure}

The study was advertised as an experiment regarding mood and taste perception, and was deliberately kept vague in order to prevent participants from predicting the true aim of the study. Experimental sessions took place between $12 \mathrm{pm}$ and $4 \mathrm{pm}$, lasting approximately $20 \mathrm{~min}$. Upon arrival, participants received an information sheet, and after providing informed consent, they were seated in individual cubicles. Participants' height and weight were measured in centimetres and kilogrammes using a stadiometer and a digital scale, and they were then instructed to complete a participant information form and the negative affect subscale. The excerpt from the movie "The Champ" was then played, and immediately after watching the clip, participants were instructed to complete the SMS and another negative affect subscale. Next, participants in the self-immersed condition and self-distanced condition were instructed to read the adapted MCD for 2 min prior to receiving the chocolate. Once participants had finished reading their adapted versions of the MCD, they were provided with the chocolate, and asked to continue engaging with MCD by considering the answers to the questions. Participants in the control condition were simply asked to taste the chocolate. All participants were informed they could eat as much or as little chocolate as they like, and should at least try to taste one

\footnotetext{
$\overline{2}$ The external eating subscale from DEBQ (van Strien et al. 1986) was collected as it was of part the original DEBQ scale. However, as the authors were only interested in exploring the effects of emotional eating and restraint eating on chocolate consumption, there was no analysis conducted on the external eating subscale.
}

chocolate from the bowl provided. After 5 min of being presented with the chocolate, the experimenter asked all participants to finish eating, and administrated a likeability question, SMS, negative affect subscale, emotional eating subscale, and restrained eating subscale. Once participants had completed the questionnaires, they were debriefed and thanked for their participation.

\section{Data Analysis}

Consumption of chocolate was initially measured in grammes, using the difference in weight of the bowl before and after each experimental session. The grammes consumed were multiplied by 5 (obtained from manufacturer's package information) in order to get a measure of total calories (kcal) consumed. Chi square was used to account for differences in gender across the three conditions, and one-way ANOVAs were conducted to test for differences in hunger, BMI, age, and chocolate intake. $3 \times 2$ ANOVAs were conducted to test for differences in negative state affect and state mindfulness scores, and ANCOVAs were used to control emotional eating and restrained eating behaviours when calculating chocolate intake across the three conditions. All analyses were conducted using SPSS v24.

\section{Results}

\section{Participant Characteristics}

One-way between-group ANOVAs found no significant differences across conditions in participants' hunger and BMI, restraint eating: all $p>.07$ (see Table 1). There was a significant difference in age $(F(2,119)=6.01, p=.01, \eta \mathrm{p} 2=.09)$, whereby age was lower amongst participants in the selfimmersed condition than those in the control condition $(p=$ $.01)$. There was also a significant difference in emotion eating $(\mathrm{F}(2,119)=3.03, p=.05, \eta \mathrm{p} 2=.05)$, whereby participants in the self-distanced condition displayed a greater emotional eating style than those in the self-immersed condition $(p=.04)$. Chi square analysis indicated gender was not equal across the three conditions $\left(X^{2}(4)=11.69, p=.02\right)$, with significantly less females present in the control condition than the selfdistanced condition $(p=.01)$. Inclusion of BMI, age, and gender as covariates in the analyses did not affect the observed results for any of the dependent measures and are therefore not discussed further.

\section{Mood Manipulation}

A 3 (condition: self-immersed, self-distanced, control) $\times 2$ (time: baseline, pre) mixed-design ANOVA was conducted in order to ensure that the movie excerpt presented induced a 
Table 1 Means, standard deviations, and significance values of variables

\begin{tabular}{|c|c|c|c|c|}
\hline & $M,(S D)$ - Self-Immersed $(n=40)$ & $M,(S D)$ - Self-Distanced $(n=40)$ & $M,(S D)-$ Control $(n=40)$ & $p$ \\
\hline Hunger & $1.70(.79)$ & $2.00(.93)$ & $2.14(.95)$ & .08 \\
\hline BMI & $21.03(9.34)$ & $24.18(7.77)$ & $21.71(8.13)$ & .22 \\
\hline Age $^{*}$ & $21.08(3.47)$ & $23.56(7.47)$ & $28.05(13.46)$ & .01 \\
\hline Emotional Eating $^{* a}$ & $26.98(9.15)$ & $32.25(9.90)$ & $29.78(9.71)$ & .05 \\
\hline Restraint Eating a & $24.15(8.88)$ & $28.03(7.15)$ & $24.75(8.02)$ & .07 \\
\hline
\end{tabular}

* significant difference across conditions

${ }^{\mathrm{a}}$ subscales of DEBQ

negative state affect amongst participants. The analysis revealed a significant main effect for time $(F(1,117)=74.72$, $p<.001, \eta \mathrm{p} 2=.39)$, no significant main effect across conditions $(F(2,117)=1.69, p=.19)$, and no significant interaction between time and condition $(F(2,117)=.63, p=.54)$. Therefore, mood manipulation appeared to be successful in all three conditions (see Table 2).

\section{State Mindfulness}

A 3 (condition: self-immersed, self-distanced, control) $\times 2$ (time: pre, post) mixed-design ANOVA was carried out to explore the effects of self-immersed MCD and self-distanced MCD on state mindfulness. There was a significant main effect across conditions $(F(2,117)=5.36, p=.01, \eta \mathrm{p} 2=.08)$, no significant main effect for time $(F(1,117)=3.11, p=.08)$, and no significant interaction between condition and time $(F(2$, $117)=.89, p=.42$ ). A post hoc comparison using the Tukey HSD test suggested participants in the self-distanced condition scored significantly higher in pre state mindfulness than those in the control condition $(p=.03)$. However, no significant differences were found between participants in self-immersed condition and self-distanced condition $(p=$ .46), or between those in the self-immersed condition and control condition $(p=.33)$. Therefore, suggesting post state mindfulness scores did not significantly increase (or decrease) across the three conditions (see Table 3).

\section{Negative State Affect}

A 3 (condition: self-immersed, self-distanced, control) $\times 2$ (time: pre, post) mixed-design ANOVA was carried out to explore the effects of self-immersed MCD and self-distanced MCD on negative state affect. There was a significant main effect for time $(F(1,117)=67.37, p=.001, \eta \mathrm{p} 2=.37)$. There was no significant main effect across condition $(F(2,117)=$ $1.81, p=.17)$, and there was no significant interaction between condition and time $(F(2,117)=1.26, p=.29)$. Thus, suggesting self-immersed MCD or self-distanced MCD had no significant effect in improving negative state affect when compared with the control condition (see Table 2).

\section{Chocolate Intake}

A one-way between-group ANOVA was conducted to explore participants' intake of chocolate across the selfimmersed condition, self-distanced condition, and control condition. There was a significant difference in chocolate intake across the three conditions $(F(2,119)=8.74, p=.001$, $\eta p 2=.13$ ) (see Table 4). A post hoc comparison using the Tukey HSD test found participants in the control condition consumed significantly more chocolate than those in the self-immersed condition $(p=.01)$ and in the self-distanced condition $(p<.001)$. However, participants in the selfimmersed and self-distanced conditions did not significantly differ in their intake of chocolate ( $p=.63$ ) (see Fig. 1).

\section{Effects of Hunger}

There appears to be a trend for participants in the control condition to report a slightly (i.e. non-significant) higher hunger rating in the control condition compared with those in the self-immersed and self-distanced conditions (see Table 1). In order to explore whether hunger had any effect upon
Table 2 Baseline, pre, and post measures of negative affect subscale

\begin{tabular}{llll}
\hline & $M,(S D)$-baseline & $M,(S D)$-pre & $M,(S D)$-post \\
\hline Self-immersed condition $(n=40)$ & $12.53(3.46)$ & $16.08(5.19)$ & $12.60(3.97)$ \\
Self-distanced condition $(n=40)$ & $13.78(4.21)$ & $18.35(7.42)$ & $14.58(4.62)$ \\
Control condition $(n=40)$ & $13.50(3.69)$ & $18.35(7.51)$ & $13.03(4.95)$ \\
\hline
\end{tabular}

$M$ and $S D$ are used to represent mean and standard deviation, respectively 
Table 3 Pre and post measures of the State Mindfulness Scale

\begin{tabular}{lll}
\hline & $M,(S D)$-pre & $M,(S D)$-post \\
\hline Self-immersed condition $(n=40)$ & $64.30(16.30)$ & $59.88(17.62)$ \\
Self-distanced condition $(n=40)$ & $68.63(13.41)$ & $68.70(15.38)$ \\
Control condition $(n=40)$ & $59.10(18.60)$ & $55.90(20.90)$ \\
\hline
\end{tabular}

$M$ and $S D$ are used to represent mean and standard deviation, respectively

participants' intake of chocolate, a between-group ANCOVA was conducted. The results suggested hunger had no significant effect on participants' chocolate intake across the three conditions $(F(1,116)=1.98, p=.16)$.

\section{Effects of Eating Behaviours}

Emotional eating and restrained eating were used as covariates to test the effect they may have had upon participants' intake of chocolate. A between-group ANCOVA indicated emotional eating had no significant effect on the amount of chocolate participants' consumed across the three conditions $(F(1,116)$ $=.35, p=.55$ ), and restrained eating also had no significant effect on participants' chocolate intake across the three conditions $(F(1,116)=2.03, p=.16)$. Therefore, suggesting the difference in the intake of chocolate across the three conditions was not because of emotional or restrained eating behaviours.

\section{Discussion}

The present study investigated whether a self-distanced MCD could improve participants' state mindfulness whilst also attenuating their negative state affect and regulating their chocolate intake. The findings suggest that participants using the self-immersed MCD or self-distanced MCD did not improve their state mindfulness or state negative affect any more (or less) than those in the control condition. However, participants in the self-immersed condition and self-distanced condition did consume significantly less chocolate than those in the control condition, and contrary to the hypothesis, there were no significant differences in participants' chocolate intake between the two experimental conditions (i.e. self-immersed and self-distanced). Emotional eating and restrained eating behaviour patterns, as well as other characteristics, such as hunger, BMI, age, and gender, had no significant effect on the findings. Overall, it appears that both self-immersed MCD and self-distanced MCD may be beneficial in reducing the overconsumption of chocolate.

Mindful eating strategies indirectly promote a moderation of consumption of unhealthy foods by encouraging people to focus on their satiety and emotional states, which in effect could lead them to eat less without affecting their mood (Kristeller and Wolever 2010). Participants using the selfimmersed MCD and self-distanced MCD did consume the least amount of chocolate (compared with those in the control condition), but their state mindfulness scores did not improve. Participants in the current study engaged with the adapted versions of the MCD for a total of $7 \mathrm{~min}$ ( 2 min reading the $\mathrm{MCD}$ before being presented with chocolate and $5 \mathrm{~min}$ spent engaging with the MCD by considering the answers to the questions whilst being presented with chocolate). Whilst a previous research has found that a 7-min framework of using the MCD is effective in improving state mindfulness (Hussein et al. 2017), participants in those settings were not experimentally induced to develop a negative affect. It is possible that participants may have needed a longer period of time engaging with the MCD to overcome their induced negative state affect and develop a state of mindfulness. In fact, the findings suggest that participants in the self-immersed and control conditions did slightly decrease in their state mindfulness scores after the experimental task, whereas in the self-distanced condition, participants' state mindfulness scores remained similar across measurements, which could potentially explain why participants in the self-distanced condition consumed significantly less chocolate than the control condition, and slightly less chocolate than those in self-immersed condition.

Participants' negative state affect appeared to improve in all three conditions, suggesting that perhaps using a selfimmersed MCD or self-distanced MCD is not any more (or less) beneficial in improving negative mood when compared with a control condition. One potential reason for improvement in mood across all three conditions may be the presence and intake of chocolate, as past research has indicated that chocolate consumption alone can improve negative mood states (e.g. Macht and Mueller 2007; Parker et al. 2006). However, it also appears that in order to improve negative state affect, participants in the control condition needed to consume significantly more chocolate than those in the selfimmersed and self-distanced conditions, suggesting that selfimmersed MCD and self-distanced MCD may both be

Table 4 Chocolate Intake

\begin{tabular}{llll}
\hline & $\begin{array}{l}\text { Self-immersed condition } \\
(n=40)\end{array}$ & $\begin{array}{l}\text { Self-distanced condition } \\
(n=40)\end{array}$ & $\begin{array}{l}\text { Control condition } \\
(n=40)\end{array}$ \\
\hline$M,(S D)-\mathrm{g}$ & $19.65(20.78)$ & $15.38(11.87)$ & $34.05(27.24)$ \\
$M,(S D)-\mathrm{kcal}$ & $98.25(103.92)$ & $76.88(59.34)$ & $170.25(136.19)$ \\
\hline
\end{tabular}

$M$ and $S D$ are used to represent mean and standard deviation of consumption of chocolate in grammes and calories 
Fig. 1 Consumption of chocolate in self-immersed condition $(n=$ $40)$, self-distanced condition $(n=$ 40 ), and control condition ( $n=$ 40). Error bars refer to the standard error of the mean. The left panel represents consumption in grammes, and the right panel represents consumption in calories

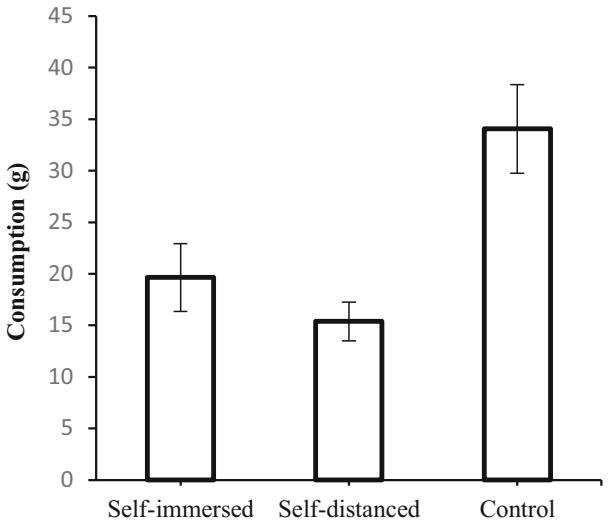

promising. Although non-significant (when compared with the self-immersed condition), participants in the selfdistanced condition did consume the least amount of chocolate whilst also improving their negative affect. Previous studies have found when participants adopt a self-distanced perspective, they are able to reflect on negative experiences adaptively, and the shift in thought content helps them reduce dwelling on sources of distress (see Ayduk and Kross 2010a, b for a review). In the present study, engaging with the self-distanced MCD may have led participant to reconstrue their experience of watching the movie fragment and focus on the broader context of the situation; i.e., the movie was fictional and therefore resulted in a prompt attenuation of negative mood without over indulging on chocolate. Therefore, the concept of self-distancing may inform interventions for reduced emotional eating with or without the MCD.

Emotional eating and restrained eating behaviours did not appear to significantly impact participants' chocolate consumption across the three conditions, and this appears to be aligned with some previous research. For example, whilst emotional eating may be a common behaviour, the amount of food that people consume to improve their mood differs greatly, and this could be based on a number of reasons, such as early childhood, cultural differences, and biological factors (e.g. Macht and Simons 2011). Furthermore, researchers have suggested that restrained eating alone does not lead to overconsumption during negative emotional states, but it is rather a combination of different factors, such as a tendency to overeat or initial hunger (e.g. Herman et al. 1987; Yeomans and Coughlan 2009). These findings suggest that eating behaviours, such as emotional and restraint, may not directly lead to overconsumption, and their effect can vary upon negative affect-induced eating.

\section{Limitations and Future Directions}

There are some potential limitations to the present study which require further attention. Firstly, this study was conducted in a highly controlled laboratory setting, and a film extract was used to induce negative affect. However, situations in real-life may not be so clear-cut; for example, in reality there may be many reasons for people to experience negative mood, such as a breakdown of a relationship or bereavement, and the emotions evoked in such situations may be longer and more detrimental. Future research investigating the role of self-distancing and eating should look to elicit negative emotions in a more authentic manner; for example, public speaking is often a method that induces anxiety and stress (Kross et al. 2014), and may be a more accurate method of negative mood induction. Another concern regarding the ecological validity of this study is the element of reading and engaging with the MCD, as this may be challenging for people in times of difficulty (e.g. low mood). Future research should investigate appropriate methods in training people to take on a more self-distanced perspective potentially through other methods of priming or nudging, and potentially utilise an audio file or simplify the instructions and usage for more effective emotion regulation.

Furthermore, the control condition was not provided with a reading or engagement task, and it could be the case that paying attention to anything whilst eating chocolate could have resulted in a reduced chocolate intake and improved mood. Therefore, future studies should include attentiongrabbing or mindless control conditions, or perhaps use the original MCD to thoroughly investigate the effects of selfdistancing in improving negative state affect and regulating chocolate consumption.

Additionally, as state mindfulness scores did not improve after using the MCD (for both self-immersed and selfdistanced conditions), caution should be taken when interpreting the current findings. In order to gain a better understanding of the mechanisms behind both the self-immersed MCD and self-distanced MCD, it may be beneficial for any future research to replicate this study by eliminating the negative affect manipulation and focus on energy intake whilst observing state changes in mindfulness. Significantly, exploring self-distancing within and outside the MCD may offer 
more insight as to what is the best way forward in designing an eating tool that is moderating intake. Furthermore, the repetitive use and longitudinal outcome should be explored as suggested in other literature to understand the regulatory potential through cognitive change and enhancement.

Finally, the current study was conducted on a relatively lean population, and people who are underweight or overweight may have had different reactions towards negative mood and chocolate intake. For example, Geliebter and Aversa (2003) found people who are underweight consumed significantly less than normal weight and overweight individuals during negative emotional states. These differences could potentially lead to distinctions in the effect of self-distancing and eating behaviours amongst underweight, normal weight, and overweight individuals. Future research should explore populations with varied BMIs in order to gain an understanding on the effects of self-distancing towards negative emotional states and eating behaviours.

\section{Conclusion}

The present study suggests that self-distancing may be beneficial in reducing the overconsumption of chocolate during a negative emotional state. Exploring this concept as a means of improving emotional eating, with or without the element of mindfulness, and mindfulness as a mindfulness outcome could potentially assist eating and weight regulation and the advancement of cognitive enhancement during eating experiences. More realistic experimental settings and populations with varied BMI categorisations may offer more insights as to how self-distancing can enable better eating behaviours and experiences in future research.

Availability of Data and Material Data and material are available on request from the corresponding author $[\mathrm{MH}]$.

Authors' Contributions $\mathrm{MH}$ designed the study, collected data, conducted data analyses, and wrote the manuscript. HE, RK, and MM supported the study and critically reviewed the manuscript. All authors gave their final approval of the manuscript.

\section{Compliance with Ethical Standards}

Conflict of Interest The authors declare that they have no conflict of interest.

Ethical Approval The study was approved by the ethical review board of the University and was in accordance with the ethical standards of the institutional and/or national research committee and with the 1964 Helsinki Declaration and its later amendments. This article does not contain any studies with animals.

Statement of Informed Consent and Consent to Participate Informed consent was obtained from all individual participants included in the study.
Open Access This article is licensed under a Creative Commons Attribution 4.0 International License, which permits use, sharing, adaptation, distribution and reproduction in any medium or format, as long as you give appropriate credit to the original author(s) and the source, provide a link to the Creative Commons licence, and indicate if changes were made. The images or other third party material in this article are included in the article's Creative Commons licence, unless indicated otherwise in a credit line to the material. If material is not included in the article's Creative Commons licence and your intended use is not permitted by statutory regulation or exceeds the permitted use, you will need to obtain permission directly from the copyright holder. To view a copy of this licence, visit http://creativecommons.org/licenses/by/4.0/.

\section{References}

Ayduk, Ö., \& Kross, E. (2010a). Analysing negative experiences without ruminating: the role of self-distancing in enabling adaptive self-reflection. Social and Personality Psychology Compass, 4(10), 841854. https://doi.org/10.1111/j.1751-9004.2010.00301.x.

Ayduk, Ö., \& Kross, E. (2010b). From a distance: implications of spontaneous self-distancing for adaptive self-reflection. Journal of Personality and Social Psychology, 98(5), 809-829. https://doi. org/10.1037/a0019205.

Canetti, L., Bachar, E., \& Berry, E. (2002). Food and emotion. Behavioural Processes, 60(2), 157-164. https://doi.org/10.1016/ s0376-6357(02)00082-7.

Dutt, S., Keyte, R., Egan, H., Hussain, M., \& Mantzios, M. (2019). Healthy and unhealthy eating amongst stressed students: considering the influence of mindfulness on eating choices and consumption. Health Psychology Report, 7(2), 113-120. https://doi.org/10.5114/ hpr.2019.77913.

Egan, H., \& Mantzios, M. (2018). A qualitative exploration of selfkindness and "treating oneself" in contexts of eating, weight regulation and other health behaviors: implications for mindfulnessbased eating programs. Frontiers in Psychology, 9. https://doi.org/ 10.3389/fpsyg.2018.00880.

Evers, C., Marijn Stok, F., \& de Ridder, D. (2010). Feeding your feelings: emotion regulation strategies and emotional eating. Personality and Social Psychology Bulletin, 36(6), 792-804. https://doi.org/10. 1177/0146167210371383.

Freitas, A. L., Gollwitzer, P. M., \& Trope, Y. (2004). The influence of abstract and concrete mindsets on anticipating and guiding others self-regulatory efforts. Journal of Experimental Social Psychology, 40(6), 739-752. https://doi.org/10.1016/j.jesp.2004.04.003.

Frisina, P., Borod, J., \& Lepore, S. (2004). A meta-analysis of the effects of written emotional disclosure on the health outcomes of clinical populations. The Journal of Nervous and Mental Disease, 192(9), 629-634. https://doi.org/10.1097/01.nmd.0000138317.30764.63.

Fujita, K., Trope, Y., Liberman, N., \& Levin-Sagi, M. (2006). Construal levels and self-control. Journal of Personality and Social Psychology, 90(3), 351-367. https://doi.org/10.1037/0022-3514. 90.3.351.

Geliebter, A., \& Aversa, A. (2003). Emotional eating in overweight, normal weight, and underweight individuals. Eating Behaviours, 3(4), 341-347. https://doi.org/10.1016/s1471-0153(02)00100-9.

Gross, J., \& Levenson, R. (1995). Emotion elicitation using films. Cognition \& Emotion, 9(1), 87-108. https://doi.org/10.1080/ 02699939508408966.

Hagemann, D., Naumann, E., Maier, S., Becker, G., Lürken, A., \& Bartussek, D. (1999). The assessment of affective reactivity using films: validity, reliability and sex differences. Personality and 
Individual Differences, 26(4), 627-639. https://doi.org/10.1016/ s0191-8869(98)00159-7.

Herman, C., Polivy, J., Lank, C., \& Heatherton, T. (1987). Anxiety, hunger, and eating behaviour. Journal of Abnormal Psychology, 96(3), 264-269. https://doi.org/10.1037/0021-843x.96.3.264.

Hussain, M., Egan, H., Keyte, R., \& Mantzios, M. (2020a) Mindful construal diaries: reducing the portion size effect [Manuscript submitted for publication]. Psychology Department, Birmingham City University.

Hussain, M., Egan, H., Keyte, R., \& Mantzios, M. (2020b) Mindful construal reflections: reducing unhealthier eating choices [Manuscript submitted for publication]. Psychology Department, Birmingham City University.

Hussain, M., Egan, H., Keyte, R., \& Mantzios, M. (2020c) The role of self-kindness in making healthier eating choices [Manuscript submitted for publication]. Psychology Department, Birmingham City University.

Hussein, M., Egan, H., \& Mantzios, M. (2017). Mindful construal diaries: a less anxious, more mindful, and more self-compassionate method of eating. SAGE Open, 7(2), 215824401770468.

Kabat-Zinn, J. (1990). Full catastrophe living: using the wisdom of your body and mind to face stress, pain and illness. New York: Delacourt.

King, L., \& Miner, K. (2000). Writing about the perceived benefits of traumatic events: implications for physical health. Personality and Social Psychology Bulletin, 26(2), 220-230. https://doi.org/10. 1177/0146167200264008.

Konttinen, H., van Strien, T., Männistö, S., Jousilahti, P., \& Haukkala, A. (2019). Depression, emotional eating and long-term weight changes: a population-based prospective study. International Journal of Behavioural Nutrition And Physical Activity, 16(1). https://doi.org/ 10.1186/s12966-019-0791-8

Kristeller, J., \& Wolever, R. (2010). Mindfulness-based eating awareness training for treating binge eating disorder: the conceptual foundation. Eating Disorders, 19(1), 49-61. https://doi.org/10.1080/ 10640266.2011 .533605

Kross, E., \& Ayduk, Ö. (2011). Making meaning out of negative experiences by self-distancing. Current Directions in Psychological Science, 20(3), 187-191. https://doi.org/10.1177/ 0963721411408883.

Kross, E., Bruehlman-Senecal, E., Park, J., Burson, A., Dougherty, A., Shablack, H., et al. (2014). Self-talk as a regulatory mechanism: how you do it matters. Journal of Personality and Social Psychology, 106(2), 304-324. https://doi.org/10.1037/a0035173.

Lazarevich, I., Irigoyen Camacho, M., Velázquez-Alva, M., \& Zepeda Zepeda, M. (2016). Relationship among obesity, depression, and emotional eating in young adults. Appetite, 107, 639-644. https:// doi.org/10.1016/j.appet.2016.09.011.

Liberman, N., \& Trope, Y. (1998). The role of feasibility and desirability considerations in near and distant future decisions: a test of temporal construal theory. Journal of Personality and Social Psychology, 75(1), 5-18. https://doi.org/10.1037/0022-3514.75.1.5.

Liberman, N., \& Trope, Y. (2008). The Psychology of Transcending the Here and Now. Science 322(5905):1201-1205.

Loxton, N., Dawe, S., \& Cahill, A. (2011). Does negative mood drive the urge to eat? The contribution of negative mood, exposure to food cues and eating style. Appetite, 56(2), 368-374. https://doi.org/10. 1016/j.appet.2011.01.011

Macht, M. (2008). How emotions affect eating: a five-way model. Appetite, 50(1), 1-11. https://doi.org/10.1016/j.appet.2007.07.002.

Macht, M., \& Dettmer, D. (2006). Everyday mood and emotions after eating a chocolate bar or an apple. Appetite, 46(3), 332-336. https:// doi.org/10.1016/j.appet.2006.01.014.

Macht, M., \& Mueller, J. (2007). Immediate effects of chocolate on experimentally induced mood states. Appetite, 49(3), 667-674. https:// doi.org/10.1016/j.appet.2007.05.004.
Macht, M., \& Simons, G. (2011). Emotional eating. In I. Nyklíček, A. Vingerhoets, \& M. Zeelenberg (Eds.), Emotion regulation and wellbeing. New York: Springer.

Macht, M., Roth, S., \& Ellgring, H. (2002). Chocolate eating in healthy men during experimentally induced sadness and joy. Appetite, 39(2), 147-158. https://doi.org/10.1006/appe.2002.0499.

Mantzios, M., \& Wilson, J. (2014). How concrete construals can become mindful: a novel approach of developing mindfulness and selfcompassion to assist weight loss. Psychology and Health, 29(4), 1-21. https://doi.org/10.1080/08870446.2013.863883.

Mantzios, M., \& Wilson, J. (2015). Exploring mindfulness and mindfulness with self-compassion-centred interventions to assist weight loss: theoretical considerations and preliminary results of a randomized pilot study. Mindfulness, 6(4), 824-835. https://doi.org/10. 1007/s12671-014-0325-z.

Mantzios, M., Egan, H., \& Asif, T. (2019). A randomised experiment evaluating the mindful raisin practice as a method of reducing chocolate consumption during and after a mindless activity. Journal of Cognitive Enhancement, 1-8. https://doi.org/10.1007/s41465-01900159-y

Mantzios, M., Skillett, K., \& Egan, H. (2020). Examining the effects of two mindful eating exercises on chocolate consumption. European Journal of Health Psychology, 26(4), 120-128. https://doi.org/10. 1027/2512-8442/a000040.

Marchiori, D., \& Papies, E. (2014). A brief mindfulness intervention reduces unhealthy eating when hungry, but not the portion size effect. Appetite, 75, 40-45. https://doi.org/10.1016/j.appet.2013. 12.009 .

Meier, B., Noll, S., \& Molokwu, O. (2017). The sweet life: the effect of mindful chocolate consumption on mood. Appetite, 108, 21-27. https://doi.org/10.1016/j.appet.2016.09.018.

Mischkowski, D., Kross, E., \& Bushman, B. (2012). Flies on the wall are less aggressive: self-distancing "in the heat of the moment" reduces aggressive thoughts, angry feelings and aggressive behaviour. Journal of Experimental Social Psychology, 48(5), 1187-1191. https://doi.org/10.1016/j.jesp.2012.03.012.

Nolen-Hoeksema, S. (1991). Responses to depression and their effects on the duration of depressive episodes. Journal of Abnormal Psychology, 100(4), 569-582. https://doi.org/10.1037/0021-843x. 100.4.569.

Parker, G., Parker, I., \& Brotchie, H. (2006). Mood state effects of chocolate. Journal of Affective Disorders, 92(2-3), 149-159. https://doi. org/10.1016/j.jad.2006.02.007.

Scholey, A., \& Owen, L. (2013). Effects of chocolate on cognitive function and mood: a systematic review. Nutrition Reviews, 71(10), 665-681. https://doi.org/10.1111/nure.12065.

Schotte, D., Cools, J., \& McNally, R. (1990). Film-induced negative affect triggers overeating in restrained eaters. Journal of Abnormal Psychology, 99(3), 317-320. https://doi.org/10.1037/0021-843x.99. 3.317 .

Tanay, G., \& Bernstein, A. (2013). State Mindfulness Scale (SMS): development and initial validation. Psychological Assessment, 25(4), 1286-1299. https://doi.org/10.1037/a0034044.

van Strien, T. (2018). Causes of emotional eating and matched treatment of obesity. Current Diabetes Reports, 18(6). https://doi.org/10. 1007/s11892-018-1000-x.

van Strien, T., Frijters, J., Bergers, G., \& Defares, P. (1986). The Dutch Eating Behavior Questionnaire (DEBQ) for assessment of restrained, emotional, and external eating behavior. International Journal of Eating Disorders, 5(2), 295-315. https://doi.org/10. 1002/1098-108x(198602)5:2<295::aid-eat2260050209>3.0.co;2-t.

Wallis, D., \& Hetherington, M. (2004). Stress and eating: the effects of ego-threat and cognitive demand on food intake in restrained and emotional eaters. Appetite, 43(1), 39-46. https://doi.org/10.1016/j. appet.2004.02.001. 
Wansink, B., Cheney, M., \& Chan, N. (2003). Exploring comfort food preferences across age and gender. Physiology \& Behaviour, 79(45), 739-747. https://doi.org/10.1016/s0031-9384(03)00203-8.

Watson, D., Clark, L., \& Tellegen, A. (1988). Development and validation of brief measures of positive and negative affect: the PANAS scales. Journal of Personality And Social Psychology, 54(6), 10631070. https://doi.org/10.1037/0022-3514.54.6.1063.
Yeomans, M., \& Coughlan, E. (2009). Mood-induced eating. Interactive effects of restraint and tendency to overeat. Appetite, 52(2), 290298. https://doi.org/10.1016/j.appet.2008.10.006.

Publisher's Note Springer Nature remains neutral with regard to jurisdictional claims in published maps and institutional affiliations. 